\title{
Analisis Daya Dukung Lingkungan Hidup Berbasis Jasa Ekosistem Penyediaan Air Bersih di Pulau Karimunjawa
}

\author{
Dian Hudawan Santosoํㅜ , Johan Danu Prasetya ${ }^{1}$, dan Deni Rahman Saputra ${ }^{1}$
}

${ }^{1}$ Jurusan Teknik Lingkungan, Fakultas Teknologi Mineral, UPN “Veteran” Yogyakarta, Jl. SWK 104 (Lingkar Utara), Condongcatur, Yogyakarta, 55283; e-mail: johan.danu@upnyk.ac.id

\begin{abstract}
ABSTRAK
Secara alamiah keberadaan Pulau Karimunjawa mampu mendukung kebutuhan hidup bagi manusia dan makhluk hidup lainnya dalam jumlah tertentu, namun seiring dengan meningkatnya pendatang sebagai wisatawan tentu sedikit banyak akan menganggu keseimbangan daya dukung dan daya tampung Pulau Karimunjawa. Ketika daya dukung dan daya tampung lingkungan hidup pada suatu daerah telah terlampui maka dampak negatif terhadap lingkungan akan muncul sehingga tidak lagi mampu mendukung dan mensuport berbagai kebutuhan untuk hidup bagi manusia yang tinggal di daerah itu. Salah satu aspek penting yang diperhitungkan dalam daya dukung dan daya tampung adalah ketersediaan air bersih. Karena itulah maka mengetahui potensi ketersediaan air bersih untuk mensuport kebutuhan masyarakat lokal maupun wisatawan di daerah penelitian sangatlah perlu. Metode yang dipakai adalah pendekatan jasa ekosistem dengan menggunakan dua proxy yaitu bentuk lahan dan tutupan lahan. Tiap-tiap proxy yang telah dideliniasi kemudian dilakukan penilaian atau pembobotan. Penilaian dan pembobotan dilakukan dengan pertimbangan penilaian para ahli atau expert judgement terhadap data ekoregion dan tutupan lahan, analisis spasial dan perhitungan indeks jasa ekosistem (IJE), serta visualisasi spasial IJE. Ground check lapangan dilakukan untuk memastikan kenampakan yang diperkirakan. Overlay dari dua proxy setelah dibobot akan menghasilkan peta jasa ekosistem penyedia air bersih. Hasil yang didapatkan adalah daerah penelitian didominasi jasa ekosistem penyedia air bersih dengan kelas tinggi seluas 1.942,94 ha atau 55,14\% dan kelas sangat tinggi seluas 12,71 ha atau 0,36\% untuk Desa Karimunjawa. Pada Desa Kemujan didominasi kelas sedang dengan luas 381,75 ha atau 10,84\%; kelas tinggi dengan luas 869,38 ha atau 24,68\%. Dengan demikkian secara umum Daya Dukung Lingkungan Hidup Pulau Karimunjawa masih mampu mendukung dan mampu menjadi penyedia air bersih yang baik begi lingkungan di sekitarnya.
\end{abstract}

Kata kunci: Air Bersih ,Daya Dukung, Jasa Ekosistem, Karimunjawa

\begin{abstract}
Naturally the existence of Karimunjawa Island is able to support and support the necessities of life for humans and other living creatures in a certain number who live on Karimunjawa Island, but along with the increase in arrivals as tourists will inevitably disrupt the balance of carrying capacity and carrying capacity of Karimunjawa Island. When the carrying capacity and carrying capacity of the environment in an area has been exceeded, a negative impact on the environment will emerge so that it is no longer able to support and support a variety of needs for life for humans who live in that area. One important aspect that is taken into account in the carrying capacity and carrying capacity is the availability of clean water. Therefore, knowing the potential availability of clean water to support the needs of local people and tourists in the study area is very necessary. The method used is the ecosystem services approach by using two proxies namely landform and land cover. Each proxy that has been delineated is then assessed or weighted. A ground check is conducted to ensure the expected appearance. Overlay of two proxies after weighting will produce a map of ecosystem services of clean water providers. The results obtained are the study area is dominated by clean water supply ecosystem services with high high classes of 1,942.94 ha or 55.14\% and very high classes of 12.71 ha or $0.36 \%$ for Karimunjawa Village. In Kemujan Village, it is dominated by medium class with an area of 381.75 ha or $10.84 \%$; high class with an area of 869.38 ha or $24.68 \%$.
\end{abstract}

Keywords: Clean Water, Carrying Capacity, Ecosystem Services, Karimunjawa

Citation: Santoso, D.H., Prasetya, J.D., dan Saputra, D.R. (2020). Analisis Daya Dukung Lingkungan Hidup Berbasis Jasa Ekosistem Penyediaan Air Bersih di Pulau Karimunjawa. Jurnal Ilmu Lingkungan, 18(2), 290-296, doi:10.14710/jil.18.2.290-296

\section{Pendahuluan}

Akses terhadap air bersih, penyediaan sanitasi yang baik, ketersediaan pangan, dan kelestarian ruang hidup menjadi target dalam pembangunan berkelanjutan (UN, 2015). Ekosistem pulau-pulau kecil memiliki kerentanan tinggi karena letaknya terpencil, ruang terbatas, sistem tertutup, dan sumber daya alam terbatas (Vergilio, M dkk, 2016). Pulaupulau kecil sangat rentan terhadap perubahan iklim, kehilangan spesies eksotis, bencana alam, dan eksploitasi sumber daya alam secara berlebihan (L. A. Nurse, 2015). Ekosistem berfungsi sebagai tempat 
proses ekologi berlangsung, mendukung kehidupan, berkembang biak, penyedia pangan, rekreasi, dan keindahan (Vergilio,M dkk, 2016). Pulau-pulau kecil memiliki ekosistem yang terbagi atas ekosistem pantai, daratan, padang lamun, mangrove, dan terumbu karang (Rangkuti dkk, 2017). Pengembangan kawasan dilindungi sebagai obyek wisata perlu direncanakan, dikelola, dan dikontrol agar berkelanjutan dalam jangka panjang (WTO, 2004). Dampak positif adanya kegiatan wisata akan mengembangkan ekonomi dan peningkatan kesejahteraan sosial penduduk lokal. Selanjutnya, dampak negatif yang timbul berupa ancaman kerusakan dan terganggunya ekosistem kawasan dilindungi tersebut (Salerno, 2013). Aktivitas wisata harus berdasarkan karakteristik dan kesesuaian dari kawasan yang dilindungi untuk obyek wisata tersebut. Tentunya, lingkungan memiliki kemampuan untuk mendukung kehidupan manusia dan mahkluk hidup lainnya sehingga terjadi keseimbangan antar keduanya yang disebut daya dukung lingkungan (Aryasa, 2017). Prinsip pengembangan kawasan wisata berkelanjutan harus dilakukan secara optimal dengan mempertahankan ekologi, konservasi, menghormati adat dan budaya, serta kepastian keberlangsungan jangka panjang (Deputi Bidang Pengembangan Destinasi dan Industri Pariwisata, 2015).

Secara alamiah keberadaan Pulau Karimunjawa mampu mensuport dan mendukung kebutuhan hidup bagi manusia dan makhluk hidup lain dalam jumlah tertentu yang tinggal di Pulau Karimunjawa, namun seiring dengan meningkatnya pendatang sebagai wisatawan tentu sedikit banyak akan menganggu keseimbangan daya dukung dan daya tampung Pulau Karimunjawa. Ketika daya dukung dan daya tampung lingkungan hidup pada suatu daerah telah terlampui maka dampak negatif terhadap lingkungan akan muncul sehingga tidak lagi mampu mendukung dan mensuport berbagai kebutuhan untuk hidup bagi manusia yang tinggal di daerah itu (Qimarudin, 2013).

Keberadaan Pulau Karimunjawa yang disertai dengan peningkatan penduduk secara tidak terkontrool telah menjadikan dan memunculkan berbagai permasalahan lingkungan hidup. Secara khusus permasalahan daya dukung air bersih menjadikan satu hal yang perlu diperhatikan oleh semua pihak. Kebutuhan akan air bersih merupakan kebutuhan utama bagi manusia dan lingkungan hidup sehingga perlu diteliti. Penelitian terkait daya dukung penyediaan air bersih di daerah penelitian belum banyak dilakukan di Pulau Karimunjawa. Untuk itulah tujuan dari penelitian ini adalah mengetahui daya dukung dan daya tampung lingkungan hidup berdasarkan jasa ekosistem penyediaan air bersih untuk mendukung kegiatan ekowisata bahari di Pulau Karimunjawa. Apakah penyediaan air bersih selama ini masih mampu mendukung aktivitas perekonomian dan wisata di Pulau Karimunjawa atau tidak. Potensi ketersediaan air bersih yang dimanfaatkan penduduk akan berubah pada saat ada kunjungan wisatawan ke Taman Nasional Karimunjawa. Pulau Karimunjawa sebagai pulau induk, menjadi titik utama kajian tentang ketersediaan serta kebutuhan air tawar di TNKJ. Hal tersebut dikarenakan Pulau Karimunjawa adalah pulau utama yang dijadikan tempat tinggal saat wisatawan melakukan berbagai kunjungan di berbagai pulau di TNKJ.

\section{Metodologi}

Data yang dikumpulkan berupa data primer dan data sekunder. Data sekunder meliputi peta citra google earth tahun 2019, peta Rupa Bumi Indonesia Karimunjawa 1410-224 skala $1: 25.000$, peta geologi regional 1: 100.000. Data primer berupa pengukuran kedalaman muka air tanah, dan pengamatan secara langsung kondisi proxy yang dinilai seperti penggunaan lahan \& bentuk lahan (ekoregion).

Untuk membuat peta daya dukung dan daya tampung berdasarkan jasa ekosistem, pertama dilakukan interpretasi tutupan lahan terlebuh dahulu. Interpretasi tutupan lahan dilakukan dengan cara mengamati dan mendelinieasi citra satelit terbaru tutupan lahan di Pulau Karimunjawa. Untuk memastikan peta yang telah dibuat agar sesuai dengan kondisi eksisting dilakukan pengecekan atau ground check lapangan.

Langkah selanjutnya adalah membuat peta ekoregion atau peta bentuk lahan. Peta bentuk lahan didapatkan dari analisis kondisi topografi dan satuan bentuk lahan di Pulau Karimunjawa. Untuk memastikan peta yang telah dibuat agar sesaui dengan kondisi eksisting dilakukan pengecekan lapangan.

Dari setiap peta yang sudah dibuat baik peta tutupan lahan maupun peta ekoregion kemudian dilakukan penilaian atau penskoraan untuk setiap jasa ekosistem. Setelah masing-masing dinilai maka kemudian dioverlay, hasil overlay kemudian dibuat klasifikasi sejumlah lima kelas dari kelas Sangat Tinggi - kelas Sangat Rendah.

Tahapan dan metode pengolahan data yang dilakukan dalam penelitian ini secara umum meliputi identifikasi jasa ekosistem dari tutupan lahan dan bentuk lahan (ekoregion), penilaian dan pembobotan jasa ekosistem berdasarkan penilaian ahli (expert judgement) terhadap data ekoregion dan tutupan lahan, analisis spasial dan perhitungan indeks jasa ekosistem (IJE), serta visualisasi spasial IJE. Hal ini dilakukan supaya hasilnya lebih optimal dan dapat dipertanggungjawabkan. Penilaian dan pembobotan jasa ekosistem oleh para ahli terhadap tutupan dan ekoregion dilakukan melalui Analytical Hierarchy Process (AHP). Sementara itu, data yang digunakan dalam penelitian ini adalah Peta Ekoregion Pulau Jawa skala 1:500.000 tahun 2013 bersumber dari Kementerian Lingkungan Hidup dan Kehutanan (KLHK), dan Peta Tutupan Lahan Pulau Jawa skala 1:250.000 tahun 2014 bersumber dari Kementerian Lingkungan Hidup dan Kehutanan (KLHK). 


\section{Hasil dan Pembahasan}

\subsection{Kondisi Geografis Daerah Penelitian}

Lokasi penelitian terletak di Kepulauan Karimunjawa secara astronomis terletak pada

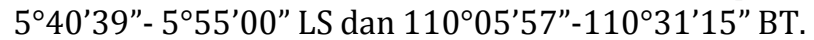
Kepulauan Karimunjawa berumur pra-tersier dengan batuan penyusun utama berupa kuarsit (quatzite) dan batusabak (shale) yang berasal dari lava basaltik (Tomascik, 1997). Jangka waktu erosi yang panjang menyebabkan terbentuknya formasi sedimen berupa sekis kristalin yang sama dengan formasi UpperTriassic flysch dari dataran sunda (Van Bemmelen, 1949). Beberapa unit bentang lahan di Kepulauan Karimunjawa antara lain topografi perbukitan berumur pra-tersier tersusun atas batuan sedimen yang terletak di Pulau Karimunjawa, topografi bergelombang berumur pra tersier tersusun atas batuan sedimen dan vulkanik pada Pulau Karimunjawa, dan Topografi datar tersusun atas alluvium dan sebagian material dari batuan sedimen maupun vulkanik hasil erosi yang tersebar di seluruh wilayah kepulauan (U. Nehren \& P. Wicaksono, 2018). Topografi perbukitan di Pulau Karimunjawa memiliki kelerengan relatif terjal $30-70 \%$. Satuan batuan penyusun pulau tersebut antara lain batuserpih filitik, batuan granitik, perselingan batupasir-lempung, batupasir kasar dan konglomerat yang umumnya terkekarkan (Hadi, 2016). Jenis tanah yaitu grumusol hitam keabuan, grumusol, dan litosol yang bersifat pasirian berukuran kasar dengan ketebalan 10-30 cm dengan tutupan lahan terdiri hutan sekunder, semak belukar, kebun, tegalan, dan sawah.

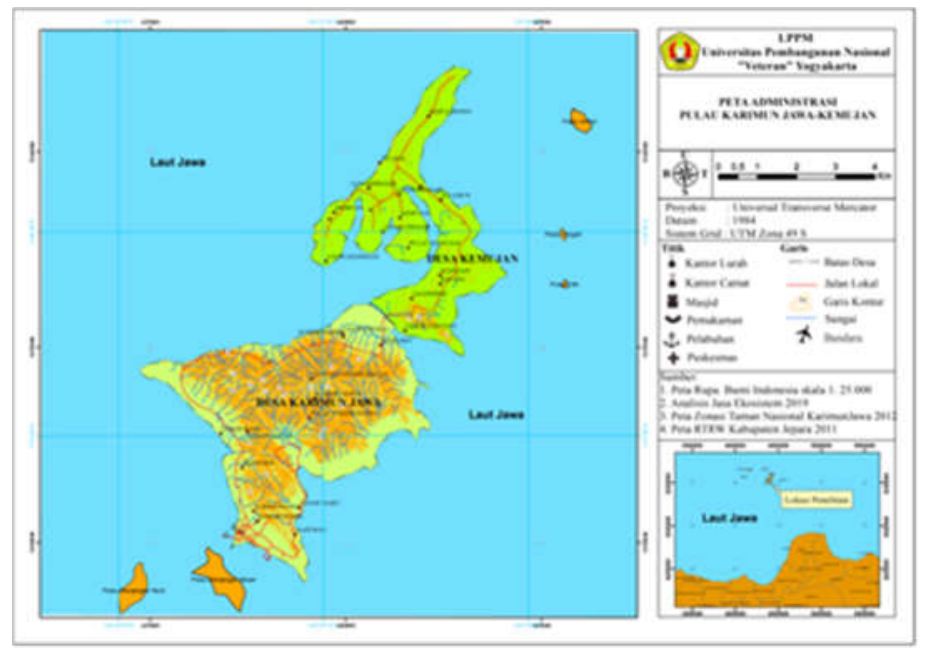

Gambar 1. Peta Administrasi Kepulauan Karimunjawa, Jawa Tengah

\subsection{Kondisi Tutupan Lahan}

Peta tutupan lahan merupakan bagian dari langkah pembuatan peta daya dukung lingkungan hidup. Peta Tutupan Lahan merupakan salah satu proxy yang harus ada sebagai dasar penyusunan daya dukung lingkungan hidup di Pulau Karimunjawa.
Berdasarkan peta tutupan lahan pada Gambar 2, daerah penelitian diketahui memiliki tutupan lahan berupa bandara udara, hutan, hutan bakau, kebun campuran, permukiman, sawah tadah hujan, semak belukar dan tambak. Luas masing dan presentase setiap penggunaan lahan disajikan dalam Tabel 1

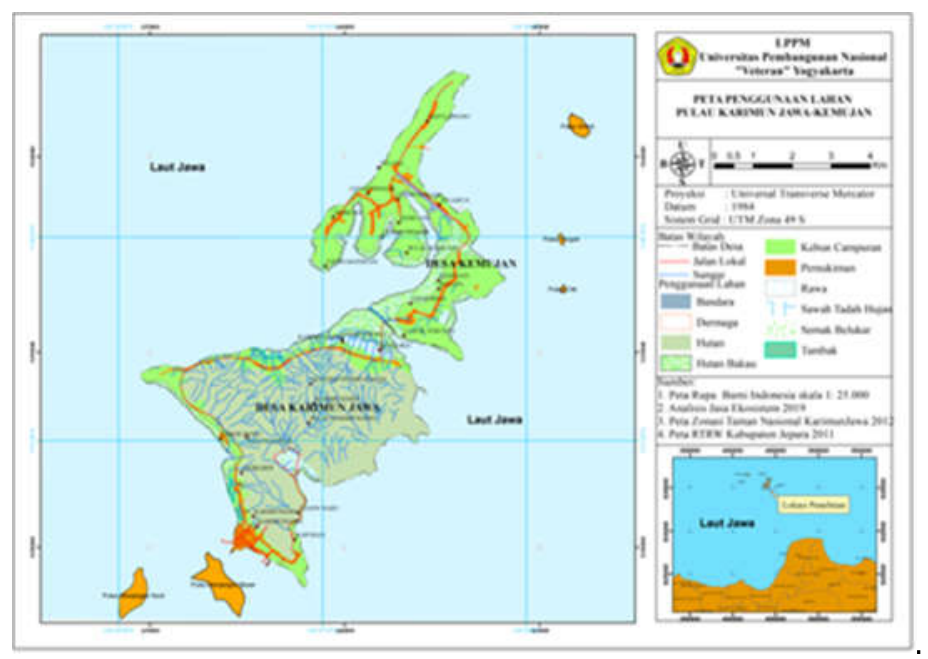

Gambar 2. Peta Tutupan Lahan Kepulauan Karimunjawa, Jawa Tengah 
Tabel 1. Presentasi luas tutupan lahan

\begin{tabular}{lcc}
\hline Tutupan Lahan & Luas (ha) & Luas \% \\
\hline Bandara & 18,4 & 0,52 \\
Hutan & $1.573,9$ & 44,69 \\
Hutan Bakau & 448,0 & 12,72 \\
Kebun Campuran & $1.175,7$ & 33,38 \\
Pemukiman & 196,7 & 5,59 \\
Sawah Tadah Hujan & 47,3 & 1,34 \\
Semak Belukar & 39,1 & 1,11 \\
Tambak & 23,0 & 0,65 \\
\multicolumn{1}{c}{$\quad$ Jumlah } & $\mathbf{3 . 5 2 2 , 0}$ & $\mathbf{1 0 0 , 0 0}$ \\
\hline
\end{tabular}

Sumber : Analisis peneliti, 2019

Berdasarkam analisis diketahui luas luas tutupan lahan terbesar di Kepulauan Karimunjawa adalah Hutan dengan presentase sebesar 44,69\%, kemudian kebun campuran 33,38\%. Sawah tadah hujan diketahui memiliki luas 47,3 hektar atau sebesar 1,34\% dari total luas wilayah Kepulauan Kariunjawa. Daerah permukiman di kepulauan Karimunjawa memiliki luas 196,7 ha atau 5,59\%.

Kondisi tutupan lahan sedikit banyak dapat menggambarkan potensi daya dukung lingkungan hidup khususnya penyediaan air bersih. Kondisi tutupan lahan di Pulau Karimunjawa diketahui didominasi oleh hutan dan kebun campuran. Keberadaan hutan dapat diindikasikan sebagai tempat yang mampu menjaga kelestarian lingkungan hidup baik berupa ketersediaan air maupun udara serta keanekaragaman flora dan fauna. Semakin banyak ketersediaan hutan maka potensi ketersediaan air bersih di daearh penelitian juga semakin besar. Hutan dapat menangkap air dan menyimpannya sebagai kawasan resapan air. Diketahui sebagaimana ditunjukkan dalam Gambar 3 di daerah penelitian terhampar hutan yang cukup luas.

\subsection{Kondisi Bentuk Lahan}

Ekoregion atau bentang lahan atau bentuk lahan adalah wilayah geografis yang memiliki kesamaan ciri iklim, tanah, air, flora, dan fauna asli, serta pola interaksi manusia dengan alam yang menggambarkan integritas sistem alam dan lingkungan hidup. Penetapan batas ekoregion dengan mempertimbangkan kesamaan bentang alam, Daerah Aliran Sungai, Keanekaragaman Hayati dan sosial budaya (UU 32 Tahun 2009).

Berdasarkan interpretasi dan analisis data diketahui daerah penelitian memiliki bentuk lahan yang bervariasi. Hal tersebut dapat diamati pada Gambar 3

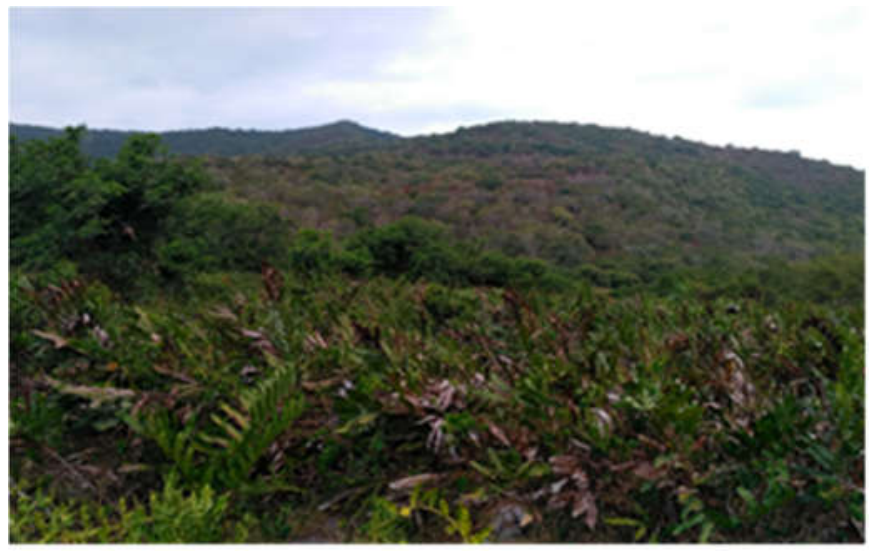

Gambar 3. Kondisi tutupan lahan berupa hutan mendominasi Pulau Karimunjawa

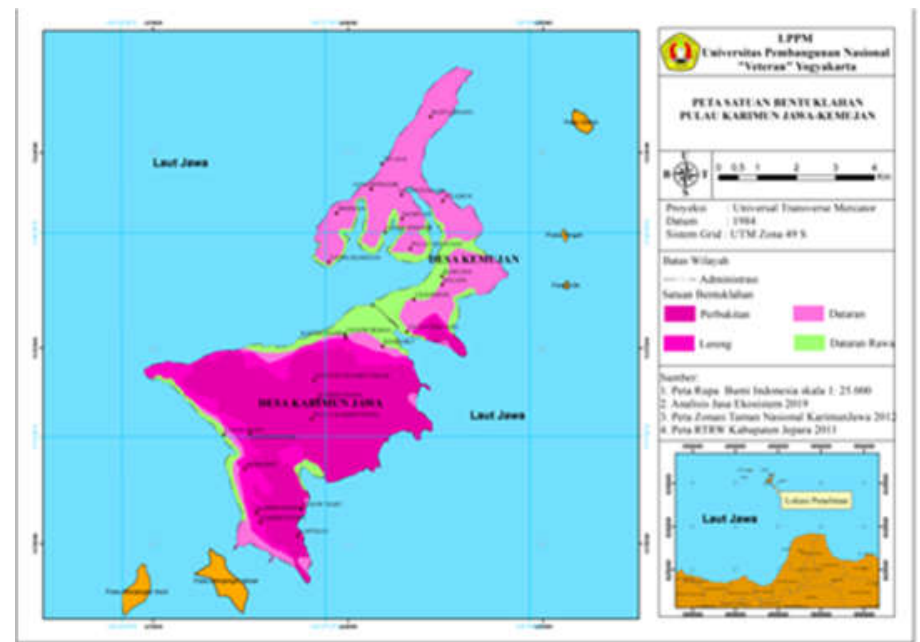

Gambar 4. Peta Bentuk Lahan Kepulauan Karimunjawa, Jawa Tengah 
Berdasarkan peta bentuk lahan tersebut daerah penelitian diketahui memiliki bentuk lahan berupa dataran, dataran rawa, lereng dan perbukitan. Luas tiap-tiap bentuk lahan disajikan dalam Tabel 2

Tabel 2. Luas bentuk lahan

\begin{tabular}{lcc}
\hline \multicolumn{1}{c}{ Bentuk lahan } & Luas (ha) & Luas (\%) \\
\hline Dataran & $1.132,3$ & 32,15 \\
Dataran Rawa & 456,4 & 12,96 \\
Lereng & 407,2 & 11,56 \\
Perbukitan & $1.526,0$ & 43,33 \\
$\quad$ Jumlah & $\mathbf{3 . 5 2 2 , 0}$ & $\mathbf{1 0 0 , 0 0}$ \\
\hline
\end{tabular}

Sumber : Analisis peneliti, 2019

Berdasarkan analisis diketahui bahwa luas bentuk lahan di daerah penelitian yang berupa perbukitan menempati area terluas yaitu sebesar 43,33\% atau sebesar 1.525 ha; bentuk lahan dataran seluas $32,15 \%$ atau $1.132,3$ hektar; bentuk lahan lereng seluas 11,56 hektar atau seluas 407,2 hektar dan bentuk lahan dataran rawa seluas 456,4 hektar atau $12,96 \%$.

Bentuk lahan perbukitan di daerah penelitian merupakan paling kluas dibanding dengan bentuk lahan yang lain. Berdasarkan kondisi di lapangan bentuk lahan perbukitan juga merupakan tutupan lahan berupa hutan. Hal ini menguatkan indikasi bahwa kondisi perbukitan di daerah penelitian juga mempunyai potensi yang besar terhadap daya dukung penyediaan air bersih. Pada bentuk lahan perbukitan juga ditemui banyak sumber mata air yang dimanfaatkan masyarakat untuk kehidupan keseharian.

\subsection{Jasa Ekosistem Penyedian Air Bersih}

Pengkajian daya dukung dan daya tampung berdasarkan jasa ekosistem penyediaan air bersih memberikan makna bahwa semakin tinggi kelas jasa ekosistem penyediaan air di suatu daerah maka akan semakin bagus kemampuan daerah tersebut dalam mendukung ketersediaan air bersih, semakin rendah kelas jasa ekosistem penyediaan air di suatu daerah maka akan semakin jelek kemampuan daerah tersebut dalam mendukung ketersediaan air bersih.

Berdasarkan hasil overlay antara peta penggunaan lahan dan peta bentuk lahan di daerah penelitian yang di dalamnya telah dilakukan proses pembobotan dengan AHP maka diperoleh peta daya dukung dan daya tampung penyediaan air bersih.

Sebagaimana Gambar 5 disajikan peta daya dukung dan dayatampung penyediaaan air bersih di daerah penelitian:

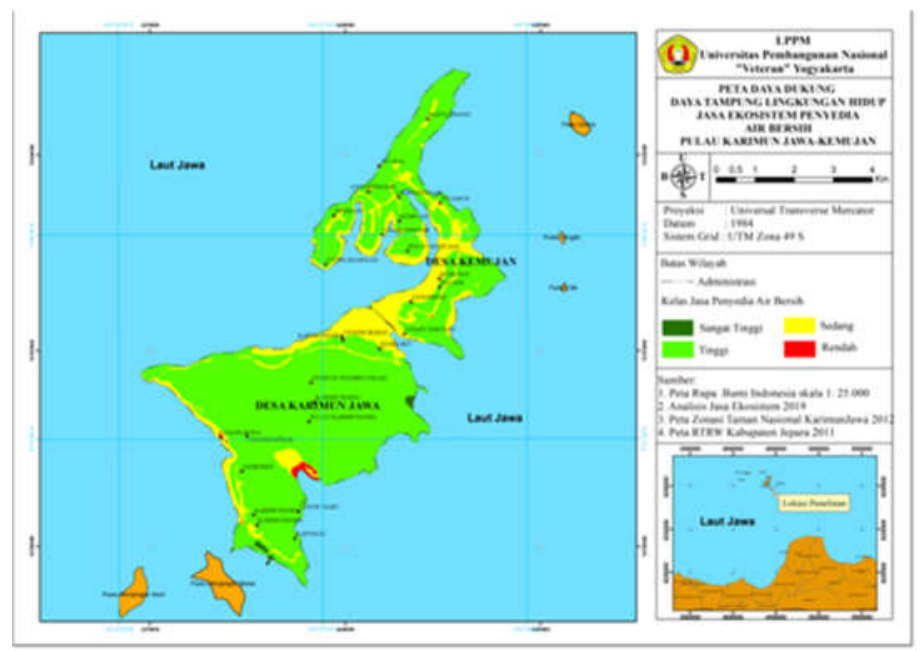

Gambar 5. Peta Daya Dukung Jasa Ekosistem Penyediaan Air Bersih

Berdasarkan analisis diketahui jumlah kelas jasa ekosistem penyediaan air bersih di Kepulauan Karimunjawa hanya sebanyak 4 kelas dari 5 kelas yang ada yaitu kelas rendah, kelas sedang, kelas tinggi dan kelas sangat tinggi. Tabel 3 merupakan analisis jasa ekosistem penyedian air bersih di daerah penelitian.

Tabel 3. Luas Kelas Jasa Ekosistem Penyedia Air Bersih

\begin{tabular}{|c|c|c|c|c|c|c|c|c|c|c|}
\hline \multirow{3}{*}{ Desa } & \multicolumn{10}{|c|}{ Luas Kelas Jasa Ekosistem Penyediaan Air Bersih (P1) } \\
\hline & \multicolumn{2}{|c|}{ Sangat Rendah } & \multicolumn{2}{|c|}{ Rendah } & \multicolumn{2}{|c|}{ Sedang } & \multicolumn{2}{|c|}{ Tinggi } & \multicolumn{2}{|c|}{ Sangat Tinggi } \\
\hline & ha & $\%$ & ha & $\%$ & ha & $\%$ & ha & $\%$ & ha & $\%$ \\
\hline Desa Karimun Jawa & - & - & 11,90 & 0,34 & 304,10 & 8,63 & $1.941,94$ & 55,14 & 12,71 & 0,36 \\
\hline Desa Kemujan & - & - & 0,17 & 0,00 & 381,75 & 10,84 & 869,38 & 24,68 & - & - \\
\hline
\end{tabular}

Sumber : Analisis peneliti, 2019 
Berdasarkan hasil analisis sebagaimana ditunjukkan dalam Tabel 3 daerah penelitian dibagi menjadi 2 desa yaitu Desa Karimunjawa dan Desa Kemujan. Pada daerah Desa Karimunjawa diketahui terdapat 4 kelas yang menunjukkan jasa ekosistem penyedia air bersih yaitu kelas rendah seluas 11,9 ha atau $0,34 \%$; kelas sedang dengan luas 304,10 ha atau $8,63 \%$, kelas tinggi seluas $1.942,94$ ha atau $55,14 \%$ dan kelas sangat tinggi seluas 12,71 ha atau $0,36 \%$.

Pada daerah Desa Kemujan diketahui terdapat 3 kelas jasa ekosistem penyedia air bersih yaitu kelas rendah dengan luas 0,17 ha; kelas sedang dengan luas 381,75 ha atau $10,84 \%$; kelas tinggi dengan luas 869,38 ha atau $24,68 \%$.

Secara umum Pulau Karimunjawa memilki kemampuan jasa ekosistem penyediaan air bersih cukup baik dimana sebagian besar luas wilayahnya didominasi oleh kemampuan jasa ekosistem penyediaan air bersih dengan kelas sangat tinggi dan tinggi. Kemampuan jasa ekosistem penyedia air bersih dengan kelas sangat tinggi merupakan kondisi dimana potensi ketersediaan air bersih di daerah penelitian sangat baik. Ditemukan banyak mata air dan sungai aliran permukaan berupa sungai musiman yang akan mengalir saat musim penghujan. Kondisi tersebut didukung oleh keberadaan tutupan lahan berupa hutan dan bentuk lahan perbukitan yang cukup dominan di Pulau Karimunjawa.

Keberadaan tutupan lahan hutan yang cukup luas mampu menjadi penjaga keseimbangan ketersediaan air di Pulau Karimunjawa. Kawasan hutan dan perbukitan merupakan area yang mampu berfungsi sebagai daerah imbuhan air atau sebagai penangkap air hujan untuk disimpan sebagai air tanah. Kondisi ini menyebabkan potensi ketersediaan air bersih di Pulau Karimunjawa cukup tinggi.

Berdasarkan kondisi pengamatan di lapangan banyak ditemukan sumber mata air di sekitar tekuk lereng perbukitan Pulau Karimunjawa. Sumber mata air yang ditunjukkan dalam Gambar 6 tersebut dapat digunakan oleh warga untuk mencukupi kebutuhan sehari-hari. Selain menggunakan sumber mata air, di daerah penelitian juga ditemukan banyak sumur gali (Gambar 7) yang berarti ketersediaan air tanah sangat cukup untuk memenuhi kebutuhan masyarakat sekitarnya.

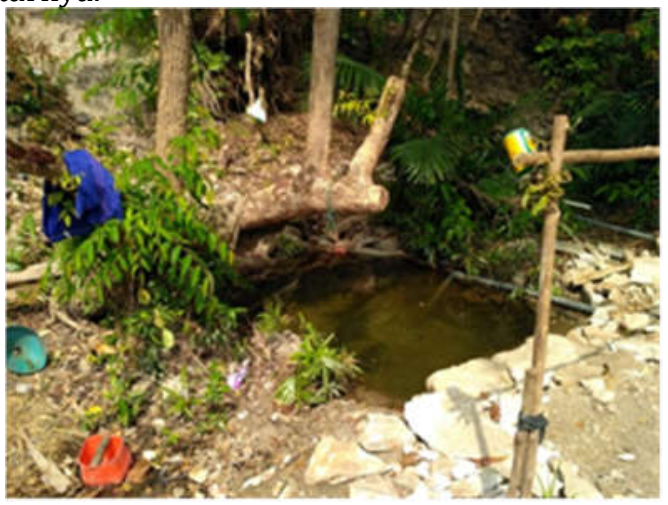

Gambar 6. Kenampakan mata air di daerah perbukitan dengan penggunaan lahan hutan

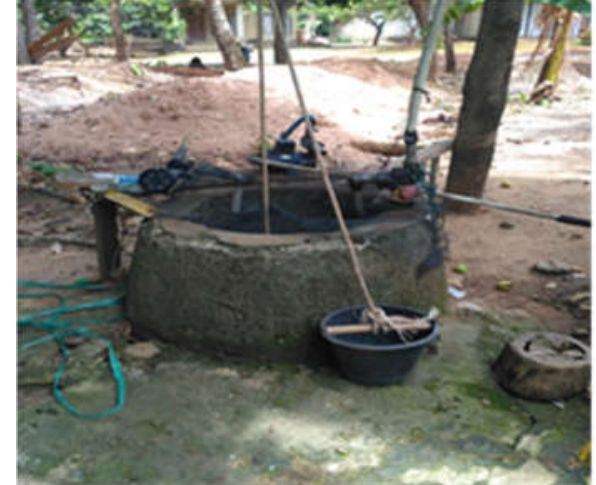

Gambar 7. Kenampakan sumur gali di daerah penelitian

Sebagian besar mata air di Pulau Karimunjawa memiliki debit yang cukup stabil baik pada musim kemarau maupun pada musim panas. Kondisi tersebut dapat disebabkan oleh beberapa faktor yaitu curah hujan yang tinggi dan daerah tangkapan yang cukup besar. Daerah imbuhan yang mampu menagkap dan menyimpan air hujan di Pulau Karimunjawa hendaknya perlu dijaka kelestarian dan fungsinya. Hal tersebut penting untuk menjaga keberlanjutan kehidupan di Pulau Karimunjawa. Beberapa hal yang perlu dilakukan untuk menjaga daerah imbuhan air sebagai sumber kehidupan adalah tidak melakukan perubahan penggunaan lahan secara besar-besaran di daerah hutan.

\section{Kesimpulan}

Berdasarkan hasil penelitian dapat disimpulkan bahwa daerah penelitian memiliki kemampuan jasa ekosistem penyediaan air cukp baik, dimana sebagian besar luas wilayahnya didominasi oleh kemampuan jasa ekosistem penyedia air dengan kelas sangat tinggi dan tinggi.

\section{Ucapan Terima Kasih}

Ucapan terima kasih yang sebesar-besarnya kepada Lembaga Penelitian dan Pengabdian Masyarakat Universitas Pembangunan Nasional "Veteran" Yogyakarta atas dukungan dan bantuan yang telah dibrikan sehingga penelitian ini dapat diselesaikan dengan baik.

\section{DAFTAR PUSTAKA}

Aryasa, A.M, A. N. Bambang, and F. Muhammad, (2017). The study of environmental carrying capacity for sustainable tourism in Telaga Warna Telaga Pengilon Nature Park, Dieng Plateu, Central Java, in IOP Conference Series: Earth and Environmental Science, 2017, vol. 70, no. 1, pp. 0-5.

B. P. S. K. Jepara, (2018). Kecamatan Karimunjawa Dalam Angka 2018

B. T. N. Karimunjawa, (2018). Statistik Balai Taman Nasional Karimunjawa (BTNK) 2018

Hadi, I.S, Arsadi, P. Hartanto, and D. Marganingrum, (2006). Kualitas Air Tanah Bebas Kota Karimunjawa, Pulau Karimunjawa. Geol. dan Pertamb., no. 2. Deputi Bidang Pengembangan Destinasi dan Industri 
Pariwisata, (2015). Rencana Strategis Pengembangan Destinasi Dan Industri Pariwisata Kementerian Pariwisata. Jakarta

Nehren U, dan P. Wicaksono, (2018). "Mappingsoil carbon stocks in an oceanic mangrove ecosystem in Karimunjawa Islands, Indonesia," Estuar. Coast. Shelf Sci., vol. 214, pp. 185-193.

Nurse, L.A. et al., (2015). Small Islands," Clim. Chang. 2014 Impacts, Adapt. Vulnerability Part B Reg. Asp. Work. Gr. II Contrib. to Fifth Assess. Rep. Intergov. Panel Clim. Chang., pp. 1613-1654.

Qomarudin (2013). Perubahan Sosial Dan Peran Masyarakat Dalam Pengembangan Kawasan Wisata Kepulauan Karimun Jawa. Journal of Educational Social Studies. Program Pascasarjana Pendidikan Ilmu Pengetahuan Sosial Universitas Negeri Semarang Indonesia

Rangkuti, Ahmad Muhtadi, Muhammad Reza Cordova, Ani Rahmawati, Yulma, dan Hasan Eldin Adimu. (2017). Ekosistem Pesisir dan Laut Indonesia. Jakarta: Penerbit Bumi Aksara.
Salerno F, G. Viviano, E. C. Manfredi, P. Caroli, S. Thakuri, and G. Tartari, (2013).Multiple Carrying Capacities from a management-oriented perspective to operationalize sustainable tourism in protected areas, J. Environ. Manage., vol. 128, pp. 116-125

Tomascik, T., Mah, A.J., Nontji, A., Moosa, M.K., (1997). The Ecology of Indonesian Seas, Part I, The Ecology of Indonesia Series, Volume VII, Periplus Editions, Singapore

Van Bemmelen, R.W. , (1949). The geology of Indonesia, Vol. 1a, general geology of Indonesia and adjacent archipelagos, Government Printing Office, The Hague, The Netherlands

Vergílio M, K. Fjøsne, A. Nistora, and H. Calado, (2016). Carbon stocks and biodiversity conservation on a small island: Pico (the Azores, Portugal), Land use policy, vol. 58, pp. 196-207.

WTO, (2014). World Overview \& Tourism Topics. 